\title{
2018 年苯乙烯车间设备现场管理经验分享
}

\section{The Management Experience Sharing of Styrene Workshop Equipment Field in 2018 \\ 常林}

Lin Chang

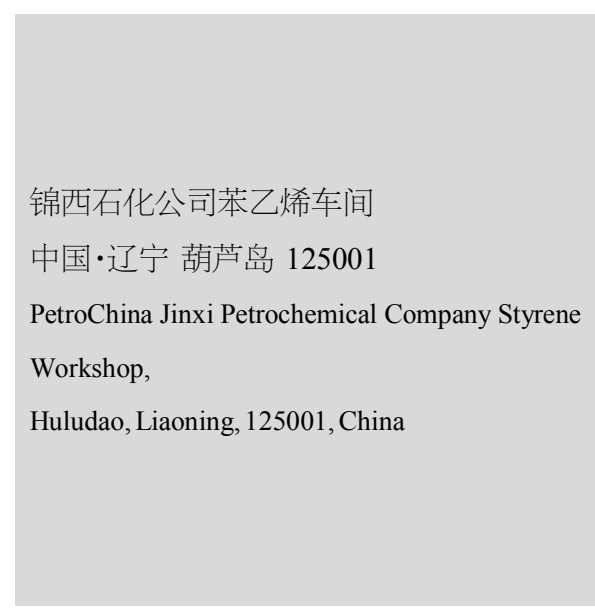

【摘要】苯乙烯车间通过进行细致的设备故障对比、执行完善的设备运行管理及设备专 项排查、完成周密的检修计划、积极进行技术攻关等等举措,在异味治理,设备平稳运行方 面取得可喜成绩。

【Abstract】Styrene workshop through a careful comparison of equipment failures, the implementation of sound equipment operation management and special equipment investigation, complete a thorough overhaul plan, actively carry out technical breakthroughs and other measures, in odor treatment, smooth operation of equipment made gratifying results.

【关键词】苯乙烯; 设备故障分析; 设备运行管理;设备专项排查;设备检修

【Keywords】Styrene; equipment failure analysis; equipment operation management; special equipment inspection; equipment maintenance

【DOI】10.36012/etr.v1i2.296

\section{1 引言}

2018 年, 苯乙烯车间将异味源治理及现场施工的安全监督 作为首要工作重点。统计全年:苯乙烯单元检修、异味源治理、 VOC 项目施工, 累计高风险作业 2000 余次, 其中, 检修历时 $30 \mathrm{~d} 、$ 项目施工贯穿全年, 工期长、作业面宽涉及苯乙烯全装置, 整个检修过程经过全车间共同努力无一起大小事故、事件发生。

锦西石化分公司的 60000t/a 乙苯-苯乙烯联合装置由乙 苯装置和苯乙烯装置两部分组成。乙苯装置采用抚顺石油二 厂、大连化物所和洛阳石化工程公司拥有的催化干气与苯烃 化制取乙苯的第三代技术, 实际规模为 $6.36 \times 10^{4} \mathrm{t} / \mathrm{a}$ 乙苯。苯 乙烯装置采用消化吸收的引进技术与国内成熟的工艺相结合 的负压脱氢技术, 实际规模为 $60000 \mathrm{t} / \mathrm{a}$ 苯乙烯。联合装置年开 工时间按 $8000 \mathrm{~h}$ 设计, 操作弹性为 60\% 110\%, 除生产目的产 品苯乙烯外, 还有副产品富丙烯干气、丙苯馏分、高沸物、烃化 尾气、甲苯、苯乙烯焦油等。

\section{2 全年设备情况汇总}

(1)共有各类设备 2455 台, 其中, 转动设备 169 台, 工艺设 备 1156 台, 电气设备 232 台,仪控设备 898 台。(2)全年设备完 好率 $99.96 \%$; 其中主要设备完好率 100\%; 静密封泄漏率 $0.247 \%$, 仪控率 $100 \%$, 联锁投用率 $100 \%$ 。(3)全年检修情况。
共检修各类设备 520 台次, 其中计划检修 505 台次,故障检修 25 台次。

\section{3 设备故障对比分析}

对比 2017 年、2018 年 2 年苯乙烯装置设备故障情况, 分 析如下:

首先, 2018 年, 苯乙烯装置尾气压缩机及干气压缩机运 行平稳, 性能可靠, 全年无因设备故障而导致的停机事件。其 中, 值得借鉴的做法有: (1)尾气压缩机喷淋水内注阻聚剂, 抑 制苯乙烯聚合, 根据往年检修情况来看, 机腔内部几乎没有苯 乙烯聚合物, 保证了机组振动、位移在正常值要求范围内。(2) 严格执行大机组日检及周检、大机组五位一体管理制度, 每月 召开大机组技术分析会, 分析设备运行情况,对其他装置大机 组发现的问题进行学习、分析、总结,将好的管理经验应用到 本装置的大机组管理上,使本装置的机组管理水平得到提高。 (3)认真、细致的巡检。在 2018 年下半年, 因为设备技术人员及 机组岗位操作人员认真细致的巡检，第一时间发现尾气压缩 机润滑油辅泵自启问题,通过仔细检查, 断定辅泵自启原因为 仪表端子问题,仪表更换现场端子排后,润滑油辅泵自启问题 得到解决, 目前机组润滑油系统运行正常。(4)2016 年, 大修准 备充分、合理。在 2016 年大检修期间, 经鉴定后, 将干气压缩 机出口冷却器的管束进行了更换, 避免了本周期内因管束泄 


\section{工程管理 Engineering Management}

漏造成机组的非计划停机事件的发生。同时，对干气压缩机 出、入口缓冲罐、分液罐的所有小接管进行了仔细的排查, 将 腐蚀减薄的小接管全部更换,消除隐患。

不足之处包括以下几方面: (1)干气中夹带部分焦泥状杂 质且含少量硫, 在 2016 年初, 造成干气压缩机非计划停机两 次; 在 2016 年大检修期间, 车间委托设计在干气压缩机入口 线增设一组可切换篮式过滤器, 但投用后发现两方面问题,一 方面干气进入篮式过滤器后可能形成浴流, 损坏滤网; 另一方 面干气中杂质较多, 过滤器堵塞频率较高。目前过滤器每 3 个 月需切换、清理滤网或更换滤网一次。(2)2018 年苯乙烯装置 换热器故障次数较多, 主要有 2 方面原因: 一是因为干气夹带 杂质较多, 造成如催化干气换热器、催化干气过冷器管束的堵 塞;二是苯塔回流罐顶冷却器( E1119)壳体腐蚀泄漏。(3)离心 泵故障率偏高的原因为个别罐区输送泵在今年安排了轮修计 划, 所以从统计上来看, 2018 年离心原的故障次数要多于 2017 年的故障次数,如图 1 所示。

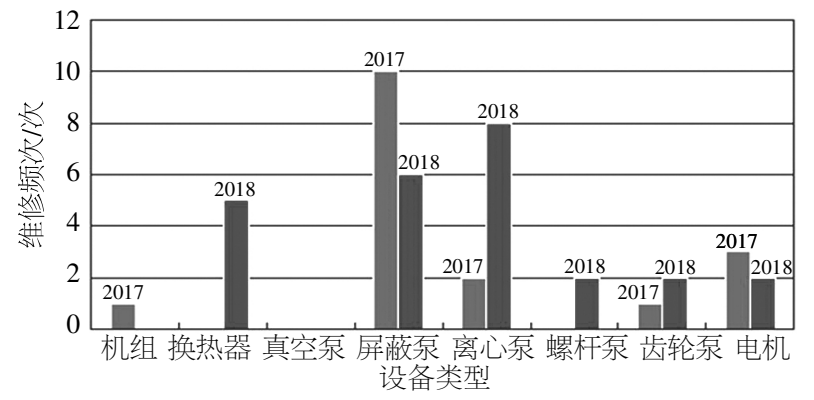

图 12017 年和 2018 年苯乙烯装置设备故障对比

\section{4 设备运行管理}

\subsection{MTBR 及机洜振动管理}

苯乙烯装置安排专人负责 MTBR 管理及机厡记性分类 分级振动管理,特别是对 $\mathrm{A}$ 类蜃采取每日一测, 对于 $\mathrm{B}$ 类百 采取两日一测, 对于 $\mathrm{C}$ 类百采取一周一测, 及时分析振动值 变化原因,超标原因,制定出相应的处理方案。

\section{2 设备腐蚀管理}

苯乙烯装置共有定点测厚点 39 点, 其中以苯塔回流罐顶 冷却器 (E1119)至苯塔回流罐顶凝液收集罐 $(V 1108)$ 一路的 管线及设备腐蚀情况最为严重。

\section{4 设备隐患管理}

苯乙烯装置共有缺陷及隐患 10 项, 其中导热油系统局部 有漏点、乙苯单元 T1104 后冷系统腐蚀严重以及乙苯单元 V1101 干气水洗效果不好, 氯离子带到后系统, 造成设备腐蚀 为设备隐患, 目前车间已经制定相应的预防措施和整改方案。

\section{5 全年设备专项排查工作}

苯乙烯车间根据车间实际情况和 2018 年公司工作重点, 编制完成 2018 年专项检查计划; 共排查专项检查包含工艺、 设备、安全环保 3 大项, 56 小项。其中重点为乙苯单元苯系统 的腐蚀专项检查、加热炉、空冷风机以及大机组的专项检查等。

\section{8 年苯乙烯单元大修总结}

\section{1 检修原因}

检修原因包括: (1)催化剂到期: 在用的乙苯脱氢催化剂自 2015 年 10 月开始使用,已超过了技术协议保证的 24 个月的 使用寿命。(2)尾气压缩机问题: 机组轴封有油漏; 汽轮机气抽 器活接卡具泄漏、负压不稳, 怀疑气抽器排液罐破水封。

\section{2 检修项目完成情况}

(1)蒸汽过热炉: 1 台。(2)反应器换剂: 2 座。(3)塔常规检修: 6 座。(4)容器计划更新:9 台; 实际更新: 8 台, 苯乙烯单元地下 罐未更换; 另有人孔打开鉴定后需要清污容器: 9 台。(5)冷换 设备计划更新: 16 台; 另有换热器常规清洗、打压:24 台。(6)压 力容器定期检验 16 台, 压力管道定期检验 3 条。(7)检修更换 工艺管线: $5138 \mathrm{~m}$; 更换划门 303 台(其中, 伴热线阀门 90 台, 倒淋阀 90 台, 瓦斯线阀门 40 台); 另有阀门打压 40 台; 拆、装 过滤器法兰口 52 片; 拆、装安全阀打压:52 台; 拆、装玻璃板 返厂修理:54 台。低老坏整改:265 项。

\section{3 检修重点问题}

6.3 .1 蒸汽过热炉 (F3301)鉴定

本次检修对加热炉进行开孔检查, 部分燃烧器长明灯存 在堵塞现象, 对其进行清理; 对流室化学清洗; 对流室钉头管 及辐射室炉管检测, 无异常; 炉内衬里有粉化现象, 修复; 看火 窗四周缝隙及炉墙砖结构部位缝隙用含锆陶纤棉维进行填塞 并用高温胶封堵完毕; 辐射室内挡火墙上部存在倾斜倒塌隐 患, 进行拆除并用耐火泥重新砌筑完毕; 对炉膛内部进行清 扫, 合格后封炉门; 将引风机单膜片型联轴器恢复为原设计蛇 簧式联轴器; 对炉顶配重进行检查并标记初始位置。

\section{3 .2 尾气压缩机消缺}

(1)检修期间重点鉴定机组入口过滤器, 滤网完好, 内部没 有杂质; 油冷器清洗鉴定合格; 水、油过滤器更换滤芯; 油站内 部清理合格、换油。(2)汽轮机气抽器蒸汽漏点已处理完, 将原 丝扣连接改为法兰连接; 目前气抽器运行良好, 现场无漏点。 (3)机组开机前, 对干气密封系统进行检查, 将前置缓冲气、主 密封气及后置隔离气压力调节正常。(4)油泵及机组联较正常; 联锁全部投用正常。 